\title{
Hedge Fund Investing or Mutual Fund Investing: An Application of Multi-Attribute Utility Theory
}

\author{
Rebecca Abraham \\ Finance and Economics, Nova Southeastern University, Fort Lauderdale, USA \\ Email: abraham@nova.edu
}

How to cite this paper: Abraham, R. (2019) Hedge Fund Investing or Mutual Fund Investing: An Application of Multi-Attribute Utility Theory. Theoretical Economics Letters, 9, 605-632. https://doi.org/10.4236/tel.2019.94042

Received: January 21, 2019

Accepted: March 25, 2019

Published: March 28, 2019

Copyright $\odot 2019$ by author(s) and Scientific Research Publishing Inc. This work is licensed under the Creative Commons Attribution International License (CC BY 4.0).

http://creativecommons.org/licenses/by/4.0/

Open Access

\begin{abstract}
This paper contrasts high-risk, hedge fund trading, with low-risk, mutual fund trading, in terms of their differing utility functions. We envision hedge funds, led by informed traders who use information to seek out investment opportunities, timing market conditions, with the expectation that prices will move in their favor. Directional hedge funds act to influence prices, while non-directional hedge funds do not act to influence prices. We present utility functions based on steeply-sloping Laplace distributions and hyperbolic cosine distributions, to describe the actions of directional hedge fund traders. Less steeply-sloping lognormal distributions, Coulomb wave functions, quadratic utility functions, and Bessel utility functions are used to describe the investing style of non-directional hedge fund traders. Flatter Legendre utility functions and inverse sine utility functions describe the modest profit-making aspirations of mutual fund traders. The paper's chief contribution is to develop optimal prices quantitatively, by intersecting utility functions with price distributions. Price distributions for directional hedge fund returns are portrayed as sharp increases and decreases, in the form of jumps, in a discrete arrival Poisson-distributed process. Separate equations are developed for directional hedge fund strategies, including event-driven arbitrage, and global macro strategies. Non-directional strategies include commodity trading, riskneutral arbitrage, and convertible arbitrage, with primarily lognormal pricing distributions, and some Poisson jumps. Mutual funds are perceived to be Markowitz portfolios, lying on the Capital Market Line, or the International Capital Market Line, tangent to the Efficient Frontier of minimum variancemaximum return portfolios.
\end{abstract}

\section{Keywords}

Utility Function, Risk Aversion, Laplace, Hyperbolic Cosine, Poisson Jumps 


\section{Introduction}

Hedge funds, which attract large cash inflows per investor, operate with minimum regulations, and strict entry barriers. Leverage, arbitrage, short selling, and derivative strategies are permitted. Only high net worth investors are included. We consider hedge funds to engage in some combination of three activities, i.e. actively seeking out investment opportunities, predicting market conditions through timing strategies, or herding to influence prices. Directional hedge funds act to move prices, while non-directional hedge funds position themselves to take advantage of information about market conditions, without actively trading to influence prices. For example, directional hedge funds predict that certain mergers are not going to be completed. They purchase the target stock, using timing to predict the date of announcement of deal failure. They short sell the stock just prior to the announcement of deal failure, earning significant gains. A non-directional hedge fund strategy could be the carry trade of borrowing funds at low-interest rates in US dollars, say at 3\%, to invest in high-interest Australian dollars, at about $8 \%$. Hedge funds have experienced record cash inflows in recent years, such as $\$ 3.21$ trillion in 2017 [1]. Performance continues to supersede expectations, with the HFRI Fund Weighted Composite Index gaining $+8.7 \%$ in 2017 , the greatest annual increase in two years [2] with December, 2017, achieving the fourteenth consecutive monthly increase in the aforementioned Index [3]. In contrast, mutual funds attract investable funds from small investors, pool the funds, investing them in stocks, bonds, or money market debt, in a passive buy-and-hold strategy. Broad diversification, professional management from fund managers, low initial investments, and easy redemption, permit small investors to participate in low-risk liquid investments in the financial markets. Prohibitions on short-selling, arbitrage, leverage, and derivatives, protect invested capital [3]. For example, an equity mutual fund would invest in a diversified portfolio of US stocks. A sector fund would invest in a particular industry, such as biotechnology. [4] reports a $6.7 \%$ return on S \& P 500 index funds in 2010-2011, though estimates of about $12 \%$ on similar funds have been observed, as well.

The core distinction between hedge fund investing and mutual fund investing lies in the attitude toward risk. While hedge fund investing uses risk-taking to generate abnormal profits, mutual fund investing is restricted by corporate practice, to modest, low-risk returns. The academic literature contrasts these risktaking and risk averse strategies. [5] described differences in compensation with higher incentive fees for hedge fund managers for superior performance, versus lower management fees for mutual fund managers for meeting fund guidelines. Another distinction lies in the extent of diversification, with few assets with idiosyncratic risk for hedge funds, contrasted with large, diversified, market risk-based portfolios for mutual funds [6]. [5] measured significant correlations of returns with idiosyncratic risk for hedge fund strategies, including capital structure arbitrage, event-driven arbitrage, fixed-income arbitrage, and glob- 
al-macro strategies. On the other hand, mutual fund portfolio returns correlated closely with market returns. Such portfolios were highly diversified, with hundreds of securities, achieving minimum risk. [7] reinforced [5]'s findings, noting the similarity of hedge fund risk to the risk inherent in options, and the underestimation of hedge fund tail risk by market models. [8] shed light on the effectiveness of hedge fund strategies, with the finding that directional hedge fund trading strategies had higher returns than non-directional hedge fund trading strategies.

The purpose of this paper is to 1) Relax the assumption of isoelastic utility that all investors have identical utility functions. 2) Specify hedge fund pricing distributions, based on Poisson jump processes, and 3) Evaluate the level of risk aversion in each investing strategy. Unlimited profit potential is sought in hedge fund investing, with highly uncertain, time-specific investments. Such upside potential does not exist for mutual funds.

The remainder of this paper is organized as follows. Section 2 consists of a Review of Literature. Section 3 develops the Proposed Quantitative Formulations of Hedge Fund Pricing, and Mutual Fund Pricing, while Section 4 provides Conclusions, and Recommendations for Future Research.

\section{Review of Literature}

\subsection{Informed Trading and Liquidity Trading}

Hedge fund traders engage in directional, or non-directional, informed trading. Applying [9]'s conceptualization, prior to an information event, such as an earnings announcement, directional informed traders purchase securities expected to report positive earnings. Market makers respond by increasing the ask prices of the securities, continuing to increase them, as hedge fund buyers herd together, driving up demand, and in turn, prices. After the day of announcement ends, security prices decline. Hedge funds short sell securities, with market makers decreasing bid prices, as hedge fund sellers sell large volumes of stock, to depress prices. Informed short sellers gain from the decline in security prices for two rounds. After this, they purchase put options, driving security prices to the minimum, to maximize gain. In this sequence, hedge funds use privileged information about the event, to direct trading. They predict the upward, or downward movement in prices, and then magnify the impact through herding. They employ timing strategies to switch rapidly from buying to selling. Empirically, [10] observed call buying on the positive signals released by acquirer stock in cash mergers, and short selling, and put buying on the negative signals released by acquirer stock in stock mergers. Similar directional hedge fund strategies occur with the global macro strategies of taking long and short positions in sector valuations, or economic trends. [11] observed a sample of hedge funds during the technology bubble, that anticipated price peaks of certain stocks, selling them before prices collapsed. [12] observed that superior market timing ability of 1453 emerging market and global macro hedge funds from 1999-2002, 
resulted in excess positive returns by limiting their exposure at the outset of economic downturns, such as currency depreciation, and debt crises. These non-diversifiable risks are contained in tail risk. Non-directional strategies do not direct trading. They employ privileged information about asset mispricing to achieve gains. They do not participate in herding to influence prices. For example, in convertible arbitrage, the trader senses that yields are rising, so invests in convertible bonds, shorting stocks that are losing value ([5]). Gains are earned on both the bond yields, and the stock short sales. [6] provided empirical evidence to support the earning of abnormal returns, in directional hedge fund strategies, contrasting them with the normal returns, earned in non-directional hedge fund investing.

Mutual fund investing originates from the creation of minimum-variance portfolios. Their objective is to minimize risk for a certain level of return. This is a risk-averse strategy, as additional risk is only accepted if additional return is guaranteed. [13] set forth an optimal set of portfolios of risk-free assets, and risky assets, which provided the highest return at minimum risk. These portfolios form the Efficient Frontier. The tangent to the Efficient Frontier, the Capital Market Line, contains the portfolios with the highest levels of utility to the investor. The Capital Market Line is always upward-sloping, as investors will only accept additional risk if they are certain of additional return. Mutual fund traders use the following Capital Market Line equation to add securities that have returns that increase in proportion to the risk of the portfolio with respect to total market portfolio risk as stated in Equation (1),

$$
R_{p}=R_{f}+\left(R_{M}-R_{f}\right) \sigma_{P} / \sigma_{M}
$$

$R=$ return on the mutual fund, $\left(R_{M}-R_{f}\right)=$ market risk premium, $\sigma_{P}, \sigma_{M}=$ standard deviation of the mutual fund and market portfolios respectively [11] replicated the [6] regression, which explained security returns as a combination of returns on asset classes, consisting of US equities, US government bonds, non-US equities, and emerging market equities. Fully $87 \%$ of the 3327 mutual funds in the Morningstar database were correlated with US equities, and US government bonds.

Mutual fund managers are liquidity traders, who engage in purchasing and selling stock, with the view to increasing their inventory of stock. They do not take advantage of price run-ups prior to information events, such as earnings surprises. There is no timing to predict the best time to buy or sell, or herding, to increase or decrease prices. They trade at prevailing bid and ask prices, set by market makers. Market makers do not adjust prices, as the lack of herding means that only a few traders demand stock at any time, so that prevailing prices do not need to be adjusted for excess demand [9].

\subsection{Risk Aversion among Hedge Fund Traders and Mutual Fund Traders}

The Miller-Swanson Schema may be used to differentiate between the attitudes 
of hedge fund traders and mutual fund traders. The Schema's entrepreneurial orientation describes individuals driven by the desire to manipulate risk to maximize income, which we may liken to the mores of hedge fund managers. This personality is contrasted with the mutual fund manager's bureaucratic orientation of favoring a low-risk, stable relationship with an employer [14]. [14] quantified the Schema by deriving expressions of income growth for both orientations. The end-period income for the entrepreneurial individual is,

$$
Y_{1}=Y_{0}+r_{e} Y_{0}
$$

The initial growth rate, $Y_{0}$, grows by a variable growth rate, $r_{e}$, to yield the final growth rate, $Y_{1}$.

For the bureaucratic orientation, the end-period income is,

$$
Y_{1}=Y_{0}+r_{b} Y_{0}
$$

The initial growth rate, $Y_{0}$, grows by a fixed growth rate, $r_{b}$, to yield the final growth rate, $Y_{1}$.

[15] found that risk-takers with low risk aversion, who were employed at mutual funds frequently sought employment at hedge funds. Their idiosyncratic risk increases were at $1.58 \%$ per month, an $85 \%$ increase over their tenure as mutual fund managers. Mutual fund managers with high levels of risk aversion, chose to remain employed at the mutual fund, reducing their idiosyncratic risk-taking by $-0.24 \%$ per month. Elevated levels of idiosyncratic risk were considered to generate the outsize returns expected of hedge fund managers. [16] found that the desire for risk-taking led hedge fund managers to acquire skills, including actively gathering a large amount of information, developing analytical skills, and demonstrating sound judgement. The ability to follow company practice in the selection of diversified portfolios that conform to market models, represents superior performance in mutual funds.

\subsection{Utility Theory Formulations of Risk Aversion}

Initial formulations of hedge fund models employed the mean-variance framework [17]. This framework sets forth the following equation, which implies the maximization of weighted means, $w^{\mathrm{T}} \mu$.

$$
\begin{aligned}
& \max w^{\mathrm{T}} \mu \\
& \mathrm{st} w^{\mathrm{T}} \Sigma w \leq \sigma_{\max }^{2}
\end{aligned}
$$

or,

$$
\max w^{\mathrm{T}} \mu-(\lambda / 2) w^{\mathrm{T}} \Sigma w
$$

where, $\lambda=$ Lagrange multiplier, coefficient of absolute risk aversion In Equation (4), the upper limit on risk is $\sigma_{\max }$, which limits the level of risk in the mean-variance portfolio. Equation (5) suggests that the maximization of portfolio return may be restricted by risk, so that investors have an incentive to reduce risk in order to achieve maximum returns. This condition is violated by hedge funds. Hedge fund portfolios have utility functions that support the achievement 
of a threshold return, followed by the pursuit of unlimited profits. [11] found that applying the mean-variance framework to a sample of hedge funds resulted in large losses over multiple time periods. Accordingly, hedge fund conditions were incorporated into future utility functions, contained in the [15] formulation of Equation (6),

$$
E\left[U\left(W_{T}^{w_{1}}\right)\right]>E\left[U\left(W_{T}^{w_{2}}\right)\right]
$$

A portfolio, $W_{1}$, with higher expectations of random wealth, $W_{T}^{w_{1}}$ is preferred to portfolio $W_{2}$, with lower expectations of random wealth, $W_{T}^{w_{2}}$. [18] [19] and [20] introduced utility functions that attempted to describe the expectations of wealth in Equation (6). However, their utility functions did not contain attitudes to risk-aversion, that differentiate between hedge fund investing and mutual fund investing. [11] created a power utility function that described the excess returns of a hedge fund over the risk-free rate, as the product of global risk aversion, $-E u^{\prime \prime}\left(1+r_{p}\right) / E u^{\prime}\left(1+r_{p}\right)$ and a total portfolio risk measure, termed omega, $\operatorname{Cov}\left(r_{p}, u^{\prime}\left(1+r_{p}\right)\right) /\left[E u^{\prime \prime}\left(1+r_{p}\right)\right]$, where $r_{p}$ is the risk of the portfolio. Hedge fund returns increased with the decrease in overall risk aversion, and increased with the extent to which hedge fund risk varied with the risk of the remainder of the portfolio, the path of variation of returns following a gamma distribution. Alternatively, [21] expressed the utility function,

$$
U(x)=x+H+(1-\Omega(H))(H-x)
$$

$H=$ threshold, and $\Omega=$ omega ratio. [21] included call and put options to model the uncertain path to the upper or lower limit of prices. Their model of wealth included a risk-free asset, $r_{p}$ returns, $\left(u-r_{f}\right)$ on $X_{0}$ shares of a risky asset, and returns on a call option, $X_{1} *\left(R_{c}-c \cdot r_{f}\right)$, where $X_{1}=$ number of call options, and $\left(R_{c}-c \cdot r_{f}\right)=$ gain per call. While these formulations provide descriptions of utility functions, they fail to provide a theoretical framework to account for hedge fund trading.

A useful distinction between hedge fund traders and mutual fund traders lies in our application of [22]'s theory of risk aversion. He maintains that absolute risk aversion is associated with the acceptance of constant certainty equivalence, while risk-taking is associated with increasing certainty equivalence. In the context of this paper, mutual fund traders, with high absolute risk aversion, accept management fees as sufficient compensation, with stable certainty equivalence. In contrast, hedge fund traders, with low absolute risk aversion, seek to earn higher and higher incentive fees. They revise the threshold certainty equivalence to a higher level, as the minimum returns that earn incentive fees rise, over time.

\subsection{Recognition of Intertemporal Substitution}

Intertemporal utility functions view utility as being derived from two or more periods. [23] obtained a utility function in which the preference for future consumption over current consumption is described by the increasing marginal 
utility of consumption growth, $\eta$. The value of Period 1's consumption < the value of Period 2's consumption, prompting the investor to invest to increase wealth in Period 2, which is then consumed in Period 2. The marginal utility, $\eta$, is the intertemporal risk aversion, which is lower in Period 2 than Period 1. Assuming a two-period time horizon, the [23] utility function, $U\left(x_{1}\right)$, that describes the dissatisfaction with Period 1 consumption is,

$$
U\left(x_{1}\right)=x_{1}^{1-\eta} /(1-\eta)+\mathrm{e}^{-\delta} /(1-\eta)\left[E_{p} x / 2^{-R R A}\right] \wedge(1-\eta) /(1-R R A)
$$

where $\delta=$ risk preference, $E_{p}=$ expected return on portfolio, $p, R R A=$ coefficient of relative risk aversion, with higher risk aversion in Period 1, over Period 2.

The limitation of Equation (8) is that it does not distinguish between risk-taking hedge funds and risk averse mutual funds, the only separability being between period 1, and period 2. [24] provided an early examination of intertemporal substitution for mutual funds in a mean-variance framework. They purchased stocks based on their expectation of market outcomes, with annual returns for 57 mutual funds showing a higher proportion of investment in the market portfolio when market returns were high, and a lower proportion of investment in the market portfolio, when market returns were low.

[25] model provided a seminal formulation for the intertemporal substitution of hedge funds. They specified the conditional probability of successive events, whereby a second event (B), follows a first event, (A). They assumed that the conditional probability of the second event followed a hypergeometric distribution in the second period, based on a normal distribution in the first period. The nonlinearity of the hypergeometric distribution accounted for the uncertain unlimited price increases, or price decreases, of a hedge fund.

In summary, this paper views the above studies as providing only partial formulations of mutual fund and hedge fund distributions, as the distributions mentioned are pricing distributions. There is no mention of utility functions intersecting with pricing distributions to yield optimal prices, an omission that this paper rectifies in Section 3. Also mutual fund studies assume that traders base returns on market outcomes, only. Stocks of multinationals are highly sensitive to exchange rates, tariffs, and events, such as Brexit. Returns on mutual funds vary widely from market returns during periods of global macroeconomic instability. Sector funds follow a particular industry sector, not the broad market. In Section 3, this paper provides a variety of formulations of both mutual fund strategies and hedge fund strategies, with a view toward developing a comprehensive framework.

\section{Findings and Analysis}

\subsection{Directional Hedge Fund Strategies}

Event-Driven Arbitrage. We will use price run-ups on stock mergers as a case of directional hedge fund trading. [10] empirically observed multimarket trading in the stock and options markets at stock merger announcements. The 
acquirer stock in a stock merger releases a negative signal, that it has insufficient cash to purchase the target, and must therefore, exchange stock. Directional hedge fund traders short sell the acquirer stock, using the proceeds to purchase the target stock. The target rises rapidly for 2 days, i.e. the day prior to merger announcement, and the day of announcement, before vanishing at the end of the day of announcement. Traders expect modest gains in short selling the acquirer stock. They benefit from exponential increases in utility, as target prices soar in Poisson jumps, exiting target purchases as prices peak, and then herd to purchase put options, maximizing gain by driving prices to a minimum. Two rounds of short selling are assumed, obtained by intersecting the hyperbolic cosine utility function [26], whose steep upward slope indicates expectations of gains from stock prices that are declining in value, with a Poisson jump price distribution.

See Figure 1 for optimal prices obtained through short selling. Point $A$ depicts the initial first round short sale price, with Point $B$ showing the final short sale price. The distance $A B$ represents the total gain from short selling. Equation (9) shows the first derivative of both the maximum likelihood estimator of the hyperbolic cosine distributed utility function and the Poisson process,

$$
\begin{aligned}
& n\left[2 e^{3 a}(1-a)-2 e^{a}(1+a) / 2 a e^{a}\left(e^{2 a}+\sum\left(1-e^{-\hat{\lambda} x i} \sinh a\left(1-e^{-\hat{\lambda} x i}\right) / \cosh a\left(1-e^{-\hat{\lambda} x i}\right)\right.\right.\right. \\
& =1 / \sqrt{ } \Pi \eta^{2} e^{\wedge}-(y-\delta)^{2} / 2 \eta^{2} d y
\end{aligned}
$$

The derivative of Equation (9) is as follows,

$$
\begin{aligned}
& n\left[2 e^{3 a}(-1)-2 e^{a}(1) / 2 a e^{a}\left(e^{2 a}+\left(1-e^{-\lambda x i} \sinh a\left(1-e^{-\lambda x i}\right) / \cosh a\left(1-e^{-\lambda x i}\right)\right.\right.\right. \\
& =\sqrt{ } / \Pi \eta e^{\wedge}-(y-\delta)^{2} / 2 \eta^{2} d y
\end{aligned}
$$

Solving for the final price, $a$, in Equation (10) yields the maximum gain from short selling. Target stock is then, purchased, with exponential increase in satisfaction as prices rise, and gains increase. An exponential utility function is assumed, which intersects with the Poisson jump process to provide first the threshold price to qualify for incentive compensation, and then, the optimal price to

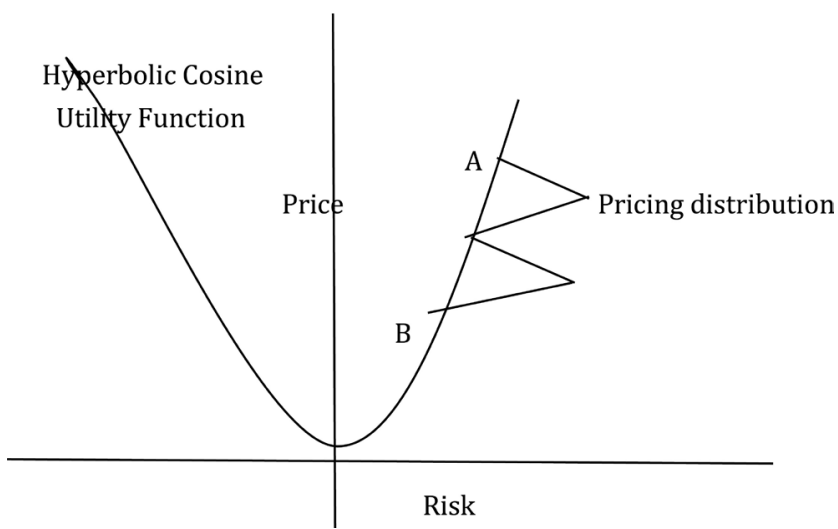

The optimal short sale price is at point $B$, with segment $A B$ representing the gain from short selling. Source: This Paper.

Figure 1. Optimal short sale prices for acquirer stock in stock mergers. 
earn profits. The omega ratio (risk measure) is elevated to the fourth power to account for kurtosis.

For a pair of securities, that are independent and identically distributed, the joint moment of expected values is,

$$
E\left[X_{i} X_{j}\right]=1 /(n-j+1) \lambda E\left[X_{i}\right]+E\left[X_{j}^{2}\right]
$$

where, $\lambda=$ rate parameter, $i<j$, [27],

The right side of Equation (11) is equated to the Ito solution to the Poisson jump process.

$$
\begin{aligned}
& 1 /(n-j+1) \lambda E\left[X_{i}\right]+E\left[X_{j}^{2}\right] \\
& =\partial g / \partial t+\mu \partial g / \partial S+\sigma^{2} / 2 \partial^{2} g / \partial S^{2}+h(t) \int_{-} \Delta g\left(g \eta_{g}(.) d \Delta g\right) d t \\
& \quad+\partial g / \partial S \sigma d W(t)+d J g(t)
\end{aligned}
$$

$S$ includes the drift, and jump, $g(S(t), t)=$ function of the jump process, $d S(t)$

$h(t)=$ stochastic process

Taking the first derivative of both sides,

$$
\begin{aligned}
& 1 /(n-j+1) \lambda E\left[X_{i}\right]+E\left[X_{j}^{2}\right] \\
& =\partial^{2} g / \partial t^{2}+\mu \partial^{2} g / \partial S^{2}+\sigma^{2} / 2 \partial^{3} g / \partial S^{3}+h(t)\left(g \eta_{g}(.) \Delta g\right) \\
& +\partial^{2} g / \partial S^{2} \sigma d^{2} W(t)+d^{2} J g(t)
\end{aligned}
$$

Taking the second derivative of Equation (12),

$$
\begin{aligned}
& 1 /(n-j+1) \lambda E\left[X_{i}\right]+E\left[X_{j}^{2}\right] \\
& =\partial^{3} g / \partial t^{3}+\mu \partial^{3} g / \partial S^{3}+\sigma^{2} / 2 \partial^{4} g / \partial S^{4}+h(t)\left(g^{2} \eta_{g}(.) \Delta g\right) \\
& +\partial^{3} g / \partial S^{3} \sigma d^{3} W^{3}(t)+d^{3} J g(t)
\end{aligned}
$$

Figure 2 shows the intersection of the exponential distribution and the Poisson jump process to achieve optimal target prices.

Omitting higher moments, and adding the omega ratio, $\Omega$, and $H$, the threshold for minimum risk, the solution for $E\left(X_{i}\right)$ and $E\left(X_{j}\right)$, yields the expected optimal price in Equation (14).

$$
\begin{aligned}
x & +H+(1-\Omega(H))^{4}(H-x)+1 /(n-j+1) \lambda E\left[X_{i}\right]+E\left[X_{j}^{2}\right] \\
= & \partial^{3} g / \partial t^{3}+\mu \partial^{3} g / \partial S^{3}+h(t)\left(g^{2} \eta_{g}(.) \Delta g\right) \\
& +\partial^{3} g / \partial S^{3} \sigma d^{3} W^{3}(t)+d^{3} J g(t)
\end{aligned}
$$

After the threshold has been reached, traders engage in herding. Traders from multiple locations purchase target stock concurrently. As trade prices $>$ the bid/ask midpoint, market makers sense a surge in demand. They increase ask prices, continuing to increase them, until the ask price $=$ bid/ask midpoint, and trading ceases, The surge in prices of target stock, from collective demand by a large number of traders may be modeled by an Esscher transformation, which is frequently used to measure collective risk [28]. 


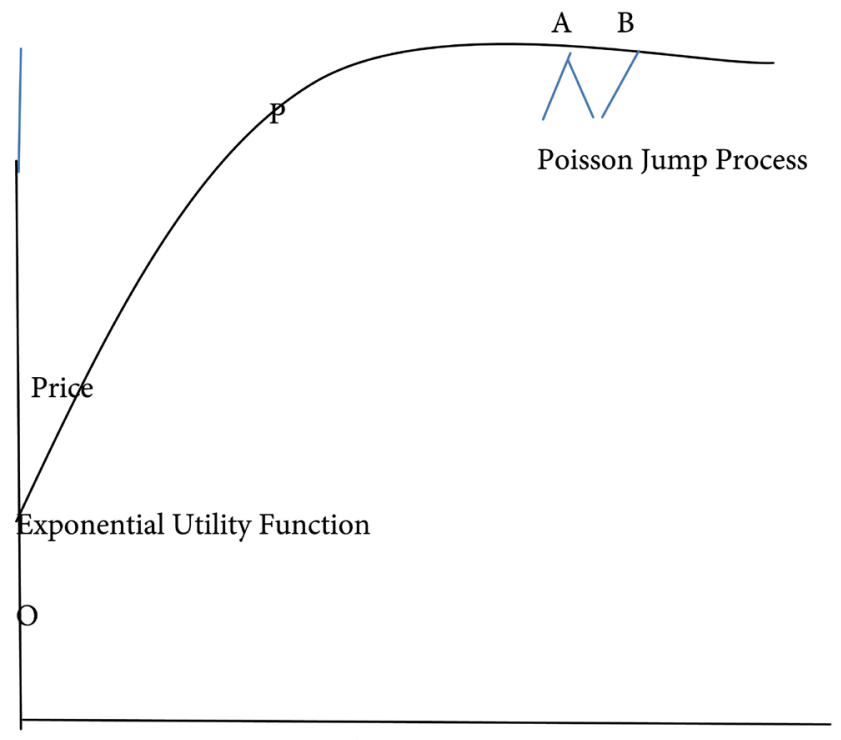

Risk

The optimal target price is at point $\mathrm{B}$, with highest return for the risk expectations of directional hedge fund traders. Source: This Paper.

Figure 2. Optimal prices for target stock at the intersection of a exponential utility function and poisson jump process.

The Esscher-transformed martingale measure, multiplies the right side of Equation (14), to magnify the impact of collective risk. Omitting the omega ratio function, which applies to the reaching of the threshold, Equation (14) transforms to

$$
\begin{aligned}
1 /(n-j+1) \lambda E\left[X_{i}\right]+E\left[X_{j}^{2}\right] \\
=\left[\partial^{3} g / \partial t^{3}+\mu \partial^{3} g / \partial S^{3}+h(t)\left(g^{2} \eta_{g}(.) \Delta g\right)+\partial^{3} g / \partial S^{3} \sigma d^{3} W^{3}(t)\right. \\
\left.\left.\quad+d^{3} J g(t)\right]\left[\exp \left\{t\left(H B+0.5 h^{2} \sigma^{2}\right)+\int\left(\mathrm{e}^{\left.h\left(e^{x-1}\right)\right)_{e}^{x}}-1 \leq 1\right\}-x 1_{\{x \leq 1\}(x)}\right) v d x\right)\right\} \\
h^{2}=\text { constant, } \sigma^{2}=\text { variance of returns, } v d x=\text { martingale process }
\end{aligned}
$$

$O P$ represents the exponential utility function, which intersects with the Poisson Jump Process at Point $A$ and Point $B$, to yield optimal target prices. Another hallmark of hedge fund trading is timing ability. When hedge fund traders complete short selling, they observe that the minimum price of the stock has not been achieved, since the uptick rule restricts short selling to two rounds. Therefore, on the day after announcement, traders drive prices to a minimum, with successive rounds of put buying. With put purchases, traders sell at high prices, market makers reduce bid prices, traders purchase at lower prices, taking gains, then sell again, taking gains at each round, until the minimum stock price is reached. Empirically. [29] observed such put trading on stock mergers from 2005-2006. Timing suggests that put option prices on acquirer stock increase, on the day after merger announcement, or the change in put prices, $d P / d x, t=$ 2 , $>d P / d x, t=1$. When this pattern continues for 30 minutes, hedge fund traders start purchasing put options. $d P / d x$, or the first derivative of the right side of Equation (15) $\rightarrow 0$. 


$$
\begin{aligned}
& d / d x=\left[\left(\partial^{4} g / \partial t^{4}+\mu \partial^{4} g / \partial S^{4}+h(t)\left(g^{3} \eta_{g}(.) \Delta g\right)\right.\right. \\
& \left.+\partial^{4} g / \partial S^{4} \sigma d^{4} W^{4}(t)+d^{4} J_{-} g(t)\right] \\
& \left.\left[\left\{t\left(H B+0.5 h^{2} \sigma^{2}\right)^{-1}+\left(e^{\left.h\left(e^{x-1}\right)\right)_{e}^{x}}-1 \leq 1\right\}-1\right) v\right)\right\} \rightarrow 0
\end{aligned}
$$

As exponential gains are expected, put buyers' utility functions follow an exponential distribution. However, there is uncertainty of earning put gains, as we do not know when the lower bound will be reached. The strengthening desire for put gain, coupled with uncertainty suggests the need for a Poisson jump process with stochastic integrals. Stochastic integrals account for collective uncertainty from all hedge fund traders, engaged in trading options on stock with underlying values. To further accommodate uncertainty, we include measures of kurtosis, for 2 random variables, $X$, and $Y$, of put option prices, to account for fat-tailed distributions. The pricing distribution for a Poisson jump process with stochastic integrals, together with kurtosis is shown in Equation (17). The cokurtosis between $X$ and $Y$ is an order 4 tensor [30].

$\exp \left(\lambda \iint\left(e^{y f^{t}}-1\right) v(d y) d t\right)+1 / \sigma_{X+Y}^{4}\left(\sigma_{X}^{4} \operatorname{Kurt}[X]+4 \sigma_{X}^{3} \sigma_{Y} \operatorname{Cokurt}[X, X, X, Y]\right.$

$\left.+6 \sigma_{X}^{2} \sigma_{Y}^{2} \operatorname{Cokurt}[X, X, Y, Y]+4 \sigma_{X} \sigma_{Y}^{3} \operatorname{Cokurt}[X, Y, Y, Y]+\sigma_{Y}^{4} \operatorname{Kurt}[Y]\right)$

Taking first derivatives of Expression (17),

$$
\begin{aligned}
& \left(\lambda \iint\left(e^{y f^{t}}-1\right) v(d y) d t\right)^{-1}+4 / \sigma_{X+Y}^{3}\left(4 \sigma_{X}^{3} 4 S k[X]+12 \sigma_{X}^{2} \sigma_{Y} \operatorname{Cosk}[X, X, X, Y]\right. \\
& \left.+12 \sigma_{Y} \operatorname{Cosk}[X, X, Y, Y]+12 \sigma_{X} \sigma_{Y}^{2} \operatorname{Cosk}[X, Y, Y, Y]+16 \sigma_{Y}^{3} \operatorname{Sk}[Y]\right)
\end{aligned}
$$

Taking second derivatives of Expression (17),

$$
\begin{aligned}
& \left(\lambda \int\left(e^{y f^{t}}-1\right) v(d y) d t\right)^{-1}+12 / \sigma_{X+Y}^{2}\left(12 \sigma_{X}^{2} 12 \operatorname{Var}[X]\right. \\
& +24 \sigma_{X} \sigma_{Y} \operatorname{Covar}[X, X, X, Y]+12 \sigma_{Y} \operatorname{Covar}[X, X, Y, Y] \\
& \left.+24 \sigma_{X} \sigma_{Y} \operatorname{Covar}[X, Y, Y, Y]+48 \sigma_{Y}^{2} 3 \operatorname{Var}[Y]\right)
\end{aligned}
$$

Equating the left side of Equation (15) with Equation (19) yields Equation (20), whose solution at $\mathrm{X}$ is the lower bound put option price.

$$
\begin{aligned}
& 1 /(n-j+1) \lambda E\left[X_{i}\right]+E\left[X_{j}^{2}\right] \\
&=\left(\lambda \int\left(e^{y f^{t}}-1\right) v(d y) d t\right)^{-1}+12 / \sigma_{X+Y}^{2}\left(12 \sigma_{X}^{2} 12 \operatorname{Var}[X]\right. \\
&+24 \sigma_{X} \sigma_{Y} \operatorname{Covar}[X, X, X, Y]+12 \sigma_{Y} \operatorname{Covar}[X, X, Y, Y] \\
&\left.+24 \sigma_{X} \sigma_{Y} \operatorname{Covar}[X, Y, Y, Y]+48 \sigma_{Y}^{2} 3 \operatorname{Var}[Y]\right)
\end{aligned}
$$

Global Macro Strategies. [5] defined global macro positions as the strategy of taking long and short positions in any world capital or derivatives market, to capitalize upon forthcoming market conditions. An example would be the dot.com bubble of 2000-2002. The dot.com bubble followed excessive speculation from 1995-2000, from the early euphoria over the introduction of the Internet [31]. [32] maintained that at the peak, the Internet sector's prices were so high that they assumed earnings growth rates for the sector would exceed the peak growth 
rates of the highest-growth rate individual firms. We describe the irrational exuberance over dot.com prices by a Laplace distribution, which is a double exponential distribution. Two exponential distributions spliced back-to-back are needed to approximate the sharp increase in satisfaction from investing in rapidly rising Internet stock. The utility function of the directional hedge fund trader may be presented as the left side of Equation (21), with a Poisson jump process on the right side.

$$
\begin{aligned}
& 0.5+0.5(\operatorname{sgn})(x-\mu)(1-\exp )(-|x-\mu| / b) \\
& =\partial g / \partial t+\mu \partial g / \partial S+\sigma^{2} / 2 \partial^{2} g / \partial S^{2}+h(t) \int_{-} \Delta g\left(g \eta_{g}(.) d \Delta g\right) d t \\
& \quad+\partial g / \partial S \sigma d W(t)+d J g(t)
\end{aligned}
$$

where $\mu=$ scale parameter, and $b=$ location parameter of the Laplace distribution Taking derivatives of both sides of Equation (21),

$$
\begin{aligned}
& 0.5(\operatorname{sgn})(1-\mu)+(|x-\mu| / b) \\
= & \partial^{2} g / \partial t^{2}+\mu \partial^{2} g / \partial S^{2}+\sigma^{2} / 2 \partial^{3} g / \partial S^{3}+h(t)\left(g^{2} \eta_{g}(.) \Delta g\right) \\
& +\partial^{2} g / \partial S^{2} \sigma d^{2} W(t)+d^{2} J g(t)
\end{aligned}
$$

Taking second derivatives of both sides of Equation (21),

$$
\begin{aligned}
& 0.5(\operatorname{sgn})(1-\mu)+(|1-\mu| / b) \\
= & \partial^{3} g / \partial t^{3}+\mu \partial^{3} g / \partial S^{3}+\sigma^{2} / 2 \partial^{4} g / \partial S^{4}+h(t)\left(g \eta_{g}(.) \Delta g\right) \\
& +3 g / \partial S^{3} \sigma d^{3} W / d W^{3}+d^{3} J+d^{3} g(t)
\end{aligned}
$$

As more traders purchased technology stocks, market makers increased ask prices, so that trade prices continually occurred above the bid-ask midpoint. Herding ensued, with synchronization of trades. A trader at one location, would place a large purchase order, with two other traders at two other locations, placing similar orders of the same size, concurrently. After six years of meteoric rise in technology prices, [33] observed that, hedge fund traders predicted that $d P / d t$, $t=1>d P / d t, t=2, d p / d t, t=2>d P / d y, t=3$, or that prices of certain technology stocks were plateauing, and sold, exiting the market. We may model this prediction of market peak as the first derivative of the pricing distribution, i.e. the right side of Equation (22) at time, $t_{1}>$ the first derivative of the pricing distribution at time, $t_{2}>$ the first derivative of the pricing distribution at time, $t_{3}$.

$$
\begin{aligned}
& \partial^{2} g / \partial t_{1}^{2}+\mu \partial^{2} g / \partial S^{2}+\sigma^{2} / 2 \partial^{3} g / \partial S^{3}+h\left(t_{1}\right)\left(g^{2} \eta_{g}(.) \Delta g\right) \\
& +\partial^{2} g / \partial S^{2} \sigma d^{2} W\left(t_{1}\right)+d^{2} J \_g\left(t_{1}\right) \\
& >\partial^{2} g / \partial t_{2}^{2}+\mu \partial^{2} g / \partial S^{2}+\sigma^{2} / 2 \partial^{3} g / \partial S^{3}+h\left(t_{2}\right)\left(g^{2} \eta_{g}(.) \Delta g\right) \\
& +\partial^{2} g / \partial S^{2} \sigma d^{2} W\left(t_{2}\right)+d^{2} J g\left(t_{2}\right) \\
& >\partial^{2} g / \partial t_{3}^{2}+\mu \partial^{2} g / \partial S^{2}+\sigma^{2} / 2 \partial^{3} g / \partial S^{3}+h\left(t_{3}\right)\left(g^{2} \eta_{g}(.) \Delta g\right) \\
& +\partial^{2} g / \partial S^{2} \sigma d^{2} W\left(t_{3}\right)+d^{2} J g\left(t_{3}\right)
\end{aligned}
$$

Other traders, who may not have invested in the same technology stocks, relied on sell signals for their stocks, which were not forthcoming. Short-sale con- 
straints prevented short selling for gain, with falling prices. Such investors continued to hold their technology portfolios, losing heavily upon market correction. Therefore, short sale constraints impose an upper bound to gaining from falling prices, as shown in Equation (25). The expression for short sale constraints, i.e. $\left(S_{e}-P\right) * V=0$, where $S_{e}=$ short sale price, $P=$ purchase price of shorted stock, $V=$ volume. intersects with Equation (23).

$$
\begin{aligned}
& 0.5(\operatorname{sgn})(1-\mu)+(|1-\mu| / b) \\
= & \partial^{3} g / \partial t^{3}+\mu \partial^{3} g / \partial S^{3}+\sigma^{2} / 2 \partial^{4} g / \partial S^{4}+h(t)\left(g \eta_{g}(.) \Delta g\right) \\
& +3 g / \partial S^{3} \sigma d^{3} W / d W^{3}+d^{3} J+d^{3} g(t) \\
= & \left(S_{e}-P\right) * V=0
\end{aligned}
$$

Figure 3 portrays the relationships discussed in this section, with $A$ and $B$ representing bubble prices for technology stocks, $C$, the unrealized short sale price, and $D$, the post-bubble minimum technology stock price.

This section has described directional hedge fund strategies, whereby traders herd to derive gains from corporate events through corporate event-driven strategies, and macroeconomic phenomena, termed global/macroeconomic events. It involves direct, timely action to influence the direction of events.

\subsection{Non-Directional Hedge Fund Strategies}

Commodity Trading on Yen Futures and New Zealand Dollar Futures. A currency futures contract is valued as the sum of its spot price (current price), and term premium (with price fluctuations during the lengthy delivery period). A non-directional hedge fund trader may borrow in yen by shorting yen futures with about $2 \%$ interest rates, and then, invest in New Zealand dollar futures with high $8.25 \%$ rates of return, gaining on the interest rate differential. This strategy is non-directional hedge fund investing, in that it employs an investment opportunity in commodities in two currencies, using timing to know when to exit

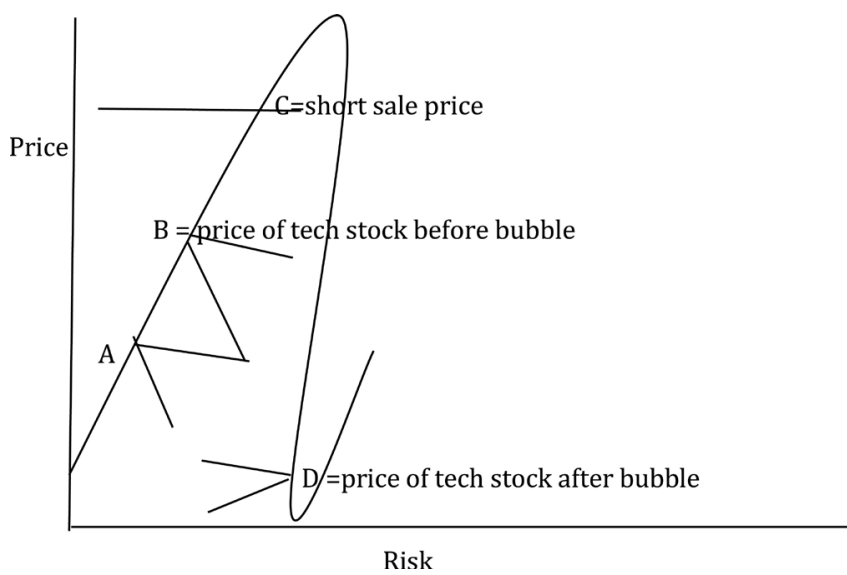

$\mathrm{B}$ is the price at which directional hedge fund traders sold to take gains. Some short selling occurred at point C. Those traders who did not predict the end of the bubble, retained stock, valued at point D. Source: This Paper.

Figure 3. Technology stock prices during the 2000-2002 bubble. 
short selling, and commence investing in NZ dollar futures. It does not use herding, to influence the direction of price movements. The utility to the hedge fund manager arises from satisfaction from a shorting-cum-investing strategy, with returns based on yield differentials between the two currencies, rather than active trading. It follows that there is gradual increase in satisfaction, which may be modeled by a lognormal distribution. The value of yen futures is based on its current spot price, which in turn, depends upon the central bank's policy of price stability, near-zero interest rates, liquidity as the third largest reserve currency in the world, and a strong trade balance with large and increasing trade inflows into Japan. [34] identified these macroeconomic variables as contributing to the yen's spot price, [35] and [36] provide empirical justification that high yen balances signal the availability of currency for purchase. Therefore, the short sale price to the hedge fund trader is based upon the distribution of the yen spot price. The appreciation of the yen may be approximated by a lognormal distribution, The lognormal distribution is the maximum entropy probability distribution for the spot price of the yen, with specified mean and variance of the $\log$ (spot price) [37]. The optimal spot price is the second derivative of each side of Equation (26),

$$
\begin{aligned}
& y_{1} \cdot\left(\sigma_{1} \sqrt{2 \Pi}\right)^{-1} \exp \left(-\frac{\left(\ln y_{1}-\mu_{1}\right)^{2}}{2 \sigma_{1}^{2}}\right) \\
& =x_{1}^{-1} \cdot\left(\sigma_{2} \sqrt{2 \Pi}\right)^{-1} \exp \left(-\left(\ln x_{1}-\mu_{2}\right)^{2} / 2 \sigma_{1}^{2}\right)
\end{aligned}
$$

where $y, \sigma_{1}, \mu_{1}$ pertain to the utility function, and $x_{1}, \sigma_{2}, \mu_{2}$ pertain to the yen.

$$
y_{1} \cdot\left(\sigma_{1} \sqrt{2 \Pi}\right)^{-1}\left(\left(\ln y_{1}-\mu_{1}\right) / \sigma_{1}^{2}\right)^{2}=x_{1}^{-1} \cdot\left(\sigma_{2} \sqrt{2 \Pi}\right)^{-1}\left(\left(\ln x_{1}-\mu_{2}\right) / \sigma_{2}^{2}\right)^{2}
$$

[38] specified a Short Roll strategy, wherein the delivery period was divided into 1-period increments, with the yen futures shorted in the first period, purchased in the second period, and re-shorted in the third period, over the delivery period, in order to gain marginally. The value of the spot price in each period, will be the previous period's spot price* $(1+$ yield $)$, as follows,

$$
\begin{aligned}
& y_{1} \cdot\left(\sigma_{1} \sqrt{2 \Pi}\right)^{-1} \exp \left(-\left(\ln y_{1}-\mu_{1}\right)^{2} / 2 \sigma_{1}^{2}\right) \\
& =x_{1}^{-1} \cdot\left(\sigma_{2} \sqrt{2 \Pi}\right)^{-1} \exp \left(-\left(\ln x_{1}-\mu_{2}\right)^{2} / 2 \sigma_{1}^{2}\right) \\
& +x_{2}^{-1}(1+r) \cdot\left(\sigma_{3} \sqrt{2 \Pi}\right)^{-1} \exp \left(-\left(\ln x_{2}-\mu_{3}\right)^{2} / 2 \sigma_{3}^{2}\right) \\
& +x_{3}^{-1}(1+r) \cdot\left(\sigma_{4} \sqrt{2 \Pi}\right)^{-1} \exp \left(-\left(\ln x_{3}-\mu_{4}\right)^{2} / 2 \sigma_{4}^{2}\right)
\end{aligned}
$$

Funds obtained from shorting yen futures may be invested in high-yield New Zealand dollar futures. [39] attributed the high yields of New Zealand dollar futures to momentum, market risk, and a global risk measure for economies with $50 \%$ of GDP from commodity-based production [40], along with a central bank policy of maintaining high interest rates. This suggests that NZ dollar futures 
will maintain high term premia during the delivery period. The optimal NZ dollar price due to the term premium will lie at the intersection of the hedge fund trader's lognormally distributed utility function, and a flat line depicting stable futures returns on the NZ dollar, due to its high and unchanging 3.5\% GDP growth rate from 2015-the present, low inflation of 1\%, and a low GDP-to-debt ratio of $28 \%$ in 2014 [41]. Taking second derivatives of each side,

$$
y_{1} \cdot\left(\sigma_{1} \sqrt{2 \Pi}\right)^{-1} \exp \left(-\left(\ln y_{1}-\mu_{1}\right)^{2} / 2 \sigma_{1}^{2}\right)=Y_{2}-a_{2}-b_{2} d^{2} X_{2} / d X_{2}^{2}
$$

where $y, \sigma_{1}, \mu_{1}$ pertain to the utility function, and $Y_{2}$ is the price, $a_{2}=$ constant, $b_{2}=$ change in NZ dollar futures for a unit change in NZ dollar risk, delivery period, only.

[38] suggested a Spreading Portfolio Strategy, in which a trader purchases NZ dollar futures at, say a 2-period maturity, shorting a 1-period futures contract, then, repeats the strategy throughout the delivery period. The momentum and risk measures that elevate NZ \$ term premia, will increase NZ \$ futures values marginally per period, as higher term premia are earned during the 2-period maturity over the 1-period maturity. Over the course of multiple periods the term premium could rise significantly above the futures price, yielding significant gain.

$$
\begin{aligned}
& y_{1} \cdot\left(\sigma_{1} \sqrt{2 \Pi}\right)^{-1} \exp \left(-\left(\ln y_{1}-\mu_{1}\right)^{2} / 2 \sigma_{1}^{2}\right) \\
& =\left(Y_{3}-a_{3}-b_{3} d^{2} X_{3} / d X_{3}^{2}-Y_{2}-a_{2}-b_{2} d^{2} X_{2} / d X_{2}^{2}\right) \\
& +\left(Y_{4}-a_{4}-b_{4} d^{2} X_{4} / d X_{4}^{2}-Y_{3}-a_{3}-b_{3} d^{2} X_{3} / d X_{3}^{2}\right)+\cdots
\end{aligned}
$$

where $Y_{3}, a_{3}, b_{3}$, and $X_{3}$ are the term premium variables for the third period, where $Y_{4}, a_{4}, b_{4}$, and $X_{4}$ are the term premium variables for the fourth period,

Adding the second derivative of the spot price from the Short Roll strategy in Equation (28) to the right side of Equation (30), yields the total optimal NZ dollar futures price, considering both current and future prices.

$$
\begin{aligned}
y_{1} & \cdot\left(\sigma_{1} \sqrt{2 \Pi}\right)^{-1} \exp \left(-\left(\ln y_{1}-\mu_{1}\right)^{2} / 2 \sigma_{1}^{2}\right) \\
= & x_{1}^{-1} \cdot\left(\sigma_{2} \sqrt{2 \Pi}\right)^{-1} \exp \left(-\left(\ln x_{1}-\mu_{2}\right)^{2} / 2 \sigma_{1}^{2}\right) \\
& +x_{2}^{-1}(1+r) \cdot\left(\sigma_{3} \sqrt{2 \Pi}\right)^{-1} \exp \left(-\left(\ln x_{2}-\mu_{3}\right)^{2} / 2 \sigma_{3}^{2}\right) \\
& +x_{3}^{-1}(1+r) \cdot\left(\sigma_{4} \sqrt{2 \Pi}\right)^{-1} \exp \left(-\left(\ln x_{3}-\mu_{4}\right)^{2} / 2 \sigma_{4}^{2}\right) \\
& +\left(Y_{3}-a_{3}-b_{3} d^{2} X_{3} / d X_{3}^{2}-Y_{2}-a_{2}-b_{2} d^{2} X_{2} / d X_{2}^{2}\right) \\
& +\left(Y_{4}-a_{4}-b_{4} d^{2} X_{4} / d X_{4}^{2}-Y_{3}-a_{3}-b_{3} d^{2} X_{3} / d X_{3}^{2}\right)+\cdots
\end{aligned}
$$

Convertible Arbitrage. [5] presents convertible arbitrage strategies as taking a long (short) position in convertible bonds, followed by taking an opposite position of short (or long) in stocks. In our conceptualization, non-directional hedge fund traders embarking upon a growth strategy would use entrepreneurial ability to seek out convertible bonds that are likely to lose value, and growth 
stocks in rapidly growing industries, such as biotechnology, renewable energy, or streaming movies. Then, they would use timing to determine the best time to short the convertible bonds, i.e. when the bonds signal a price decline. Price declines are likely to occur, upon the announcement of the Federal Reserve's announcement of an interest rate increase, or a negative monthly jobs report from the U.S. Department of Labor. The trader employs a Coulomb wave distributed utility function. A drop in bond values occurs. Convertible bond investors are unlikely to demonstrate sharp increases in satisfaction. Their utility function has more gradual trajectories, which could be approximated by an irregular Coulomb wave function. An irregular function is preferred, as the waves are likely to be of different size, with different responses to price declines during each round of short selling. The intersection of the irregular Coulomb wave function, $G(\eta, \rho)$, and the lognormal price distribution of convertible bonds, after two rounds of short selling, is shown in Equation (32) and Equation (33). The strategy consists of short selling the convertible bonds, repurchasing the convertible bonds at a reduced price, taking a gain, short selling the convertible bonds, and repurchasing at a reduced price for maximum gain.

$$
\begin{aligned}
& 2 \eta / C_{0}^{2}(\eta) F_{L}(\eta, \rho)\left[\ln 2 \rho+q_{L}(\eta) / \rho_{L}(\eta)\right]+2 /(2 L+1)^{-L} \sum \alpha_{L}^{L}(\eta) \rho^{k+L} \\
& =x_{1}^{-1} \cdot\left(\sigma_{2} \sqrt{2 \Pi}\right)^{-1} \exp \left(-\left(\ln x_{1}-\mu_{2}\right)^{2} / 2 \sigma_{1}^{2}\right)
\end{aligned}
$$

Taking first derivatives of both sides,

$$
\begin{aligned}
& 2 \eta / C_{0}^{2 \prime}(\eta) F_{L}^{\prime}(\eta, \rho)\left[1 / 2 \rho+q_{L}^{\prime}(\eta) / \rho_{L}^{\prime}(\eta)\right]+2 /(2 L+1)^{-L} \alpha_{L}^{L}(\eta) \rho^{k+L} \\
& =x_{1}^{-2} \cdot\left(\sigma_{2} \sqrt{2 \Pi}\right)^{-2} \exp \left(-\left(\ln X_{1}-\mu_{2}\right)^{2} / 2 \sigma_{1}^{2}\right)
\end{aligned}
$$

Taking second derivatives of Equation (32), yields the optimal short sale price,

$$
\begin{aligned}
& 2 \eta / C_{0}^{2 \prime \prime}(\eta) F_{L}^{\prime \prime}(\eta, \rho)\left[-1 / 2 \rho^{2}+q_{L}^{\prime \prime}(\eta) / \rho_{L}^{\prime \prime}(\eta)\right]+2 /(2 L+1)^{-L} \alpha_{L}^{L^{\prime}}(\eta) \rho^{k+L} \\
& =2 x_{1}^{-3} \cdot\left(\sigma_{2} \sqrt{2 \Pi}\right)^{-3}\left(-\left(1 / X_{1}-\mu_{2}\right)^{2} / 2 \sigma_{1}^{2}\right)
\end{aligned}
$$

Figure 4 depicts relationships in Equations (32)-(33). The distance $A B$ represents the short sale gain.

The convertible bond is converted to growth stocks. The investment in growth stocks requires an expectation of rising utility (satisfaction) with rising prices. Yet, the expectations of growth will not be as rapid as before a merger, suggesting that a controlled increase in utility, with rising prices, such as a Bessel function, be employed to describe the utility function of the non-directional trader (see Equation (34)).

$$
=\left(0.5 z^{v}\right) \sum_{k=0}^{\infty}\left[\left(-0.25 z^{2}\right)^{k} / k ! \Gamma(v+k+1)\right]
$$

where $z=$ a plane cut along the negative real axis, $V=$ the first derivative of the Bessel function, $k=$ constant

Taking first derivatives of Equation (34). 


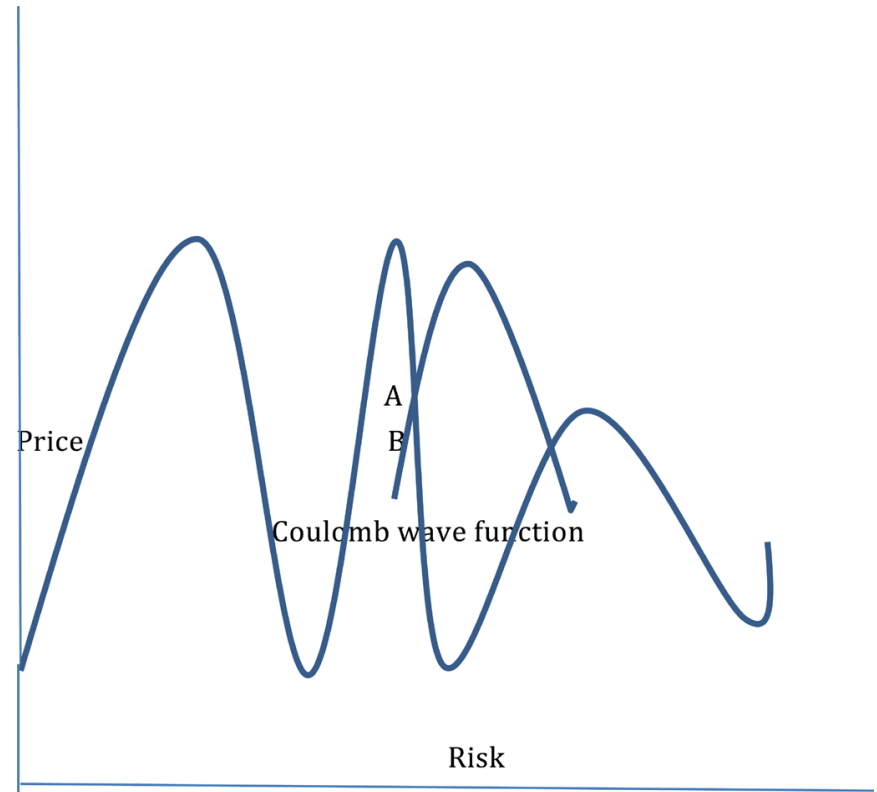

Figure shows the proceeds from short selling convertible bonds, $A B$ on falling bond prices in a convertible arbitrage strategy. Source: This Paper.

Figure 4. Proceeds of the short sale of convertible bonds.

$$
=\left(0.5 z^{v}\right)\left[\left(-0.25 z^{2}\right)^{k} / k ! \Gamma(v+k+1)\right]
$$

Taking second derivatives of Equation (34),

$$
=\left(0.5 v z^{v-1}\right)\left[(-0.25 z)^{k} / k ! \Gamma^{\prime}(1+k)\right]
$$

Equating Equation (35)'s Bessel utility function with the second derivative of the Poisson jump process,

$$
\begin{aligned}
& \left(0.5 v z^{v-1}\right)\left[(-0.25 z)^{k} / k ! \Gamma^{\prime}(1+k)\right] \\
& =\partial^{3} g / \partial t^{3}+\mu \partial^{3} g / \partial S^{3}+\sigma^{2} / 2 \partial^{4} g / \partial S^{4}+h(t)\left(g \eta_{g}(.) \Delta g\right) \\
& +3 g / \partial S^{3} \sigma d^{3} W / d W^{3}+d^{3} J+d^{3} g(t)
\end{aligned}
$$

Solving for $z$ in Equation (36), yields the optimal stock price, for maximum gain.

Figure 5 depicts the relationships in Equations (34)-(36), The optimal price occurs at Point $P$.

Non-directional hedge fund strategies seek entrepreneurial opportunities for profit-making, using timing to purchase at low prices and sell at high prices. These strategies demonstrated a sophisticated understanding of the direction of market movements, like those of directional hedge fund traders. They are distinguished from directional hedge fund strategies, in that they do not employ herding to influence the direction of price movements.

\subsection{Mutual Fund Strategies}

Sector Funds Theory. Mutual fund traders are liquidity traders. Liquidity traders 


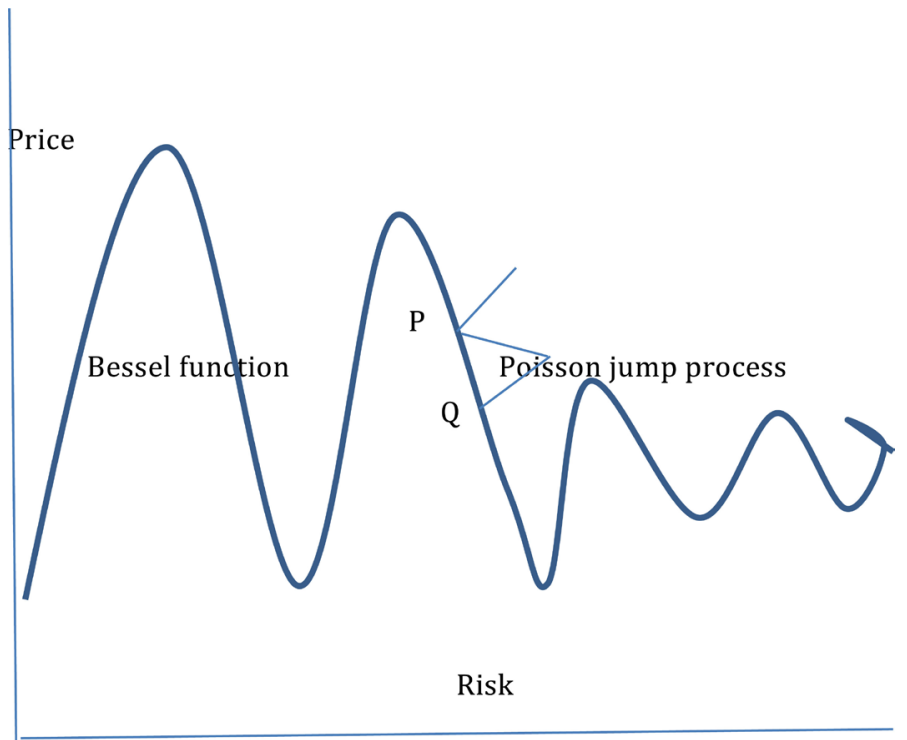

Figure shows the gain from purchasing growth stocks. $P$ is the optimal price from rising stock prices in a convertible arbitrage strategy. Source: This Paper.

Figure 5. The optimal price from a growth stock investment strategy.

emphasize the minimization of risk, as specified by the [13] and [6] models. In the creation of a biotechnology sector portfolio, the fund manager selects a large number of biotechnology stocks, with moderate risk. Portfolios eschew the highly risky, small biotechnology firms that are engaged in the production of limited volume drugs to treat rare diseases, in favor of drug producers that have broader market potential. For example, stocks of firms that release diabetes drugs, are likely to be included, while those that treat a rare liver disease are unlikely to be included. Mutual fund traders do not time the market. Their purchasing or selling is based on whether the biotechnology firms have long-term growth potential. They do not attempt to benefit from price run-ups during events, such as the introduction of a breakthrough treatment, earnings announcements, dividend announcements, merger announcements, or reorganization. The mutual fund sector portfolio is located on the Capital Market Line, which is tangent to the Markowitz minimum-variance frontier of minimum risk portfolios. The equation to the Capital Market Line is listed in Equation (37),

$$
R_{j}=R_{f}+\sigma_{j} / \sigma_{M} \cdot\left(R_{M}-R_{f}\right)
$$

where $R_{j}=$ return on the stock, $\sigma_{j}=$ risk of biotechnology stock, $R_{M}-R_{f}$

$$
\sigma_{M}=\text { market risk, } R_{M}-R_{f}=\text { market risk premium, }
$$

The risk of the biotechnology stock increases portfolio risk substantially, so that maintaining a diversified portfolio is used to reduce this risk to just above the market risk, shown in Figure 6, as lying, at point $F$, just to the right of the intersection of the market portfolio with the Capital Market Line, $P$.

The utility function for the mutual fund manager may be expressed as the following Legendre integral, $S T$, which intersects with the Capital Market Line at point $F$, in Figure 6, This relationship is expressed in Equation (38), 


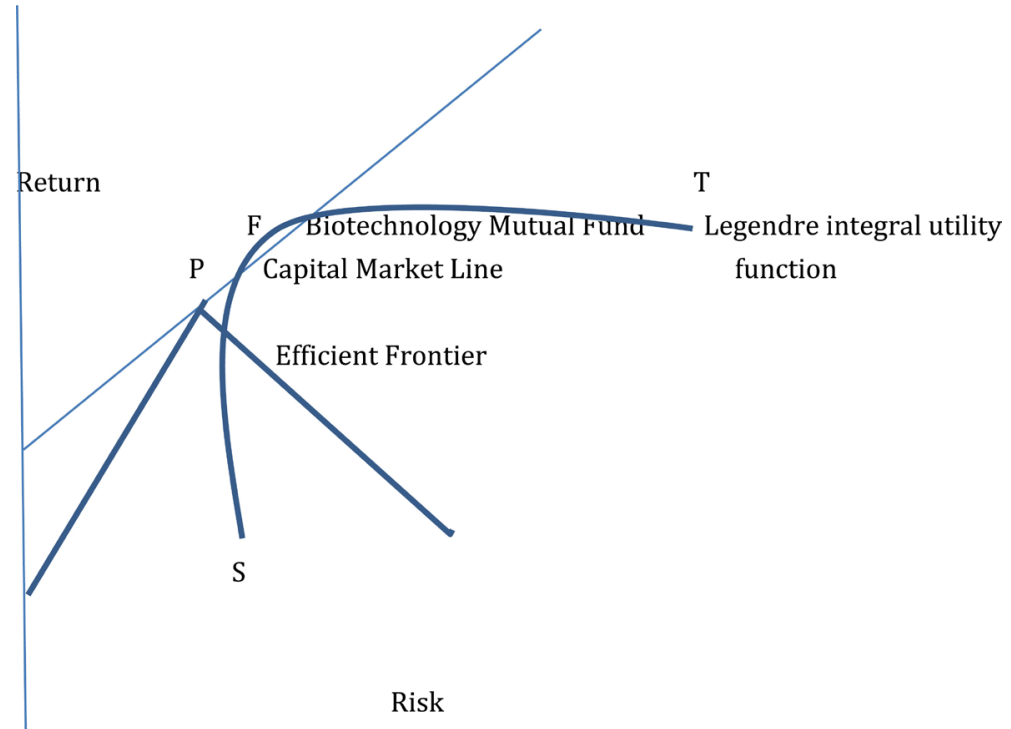

Figure shows the optimal biotechnology fund price, $F$, at the intersection of the mutual fund trader's Legendre utility function and the Capital Market Line. Source: This Paper.

Figure 6. Location of the biotechnology mutual fund on the capital market line.

$$
\left(1-z^{2}\right) d^{2} / d z^{2} 2 z \cdot d w / d z+\left[v(v+1) \mu^{2} /\left(1-z^{2}\right)\right] w=0
$$

With degree $V$, and order $\mu$, with singularities at $\pm 1, \alpha$, as ordinary branch points $-\mu, v$, arbitrary complex constants. $Z=X+1, y, z$ are real numbers in the interval $-1 \leq+1$. The Arrow-Pratt risk aversion is multiplied by the left side of Equation (38), and the right side is equated to the Capital Market Line, which acts as the pricing distribution,

$$
\left(1-z^{2}\right) d^{2} / d z^{2} 2 z \cdot d w / d z+\left[v(v+1) \mu^{2} /\left(1-z^{2}\right)\right]
$$

Taking second derivatives of Equation (38), and multiplying by the Arrow-Pratt Risk aversion, and equating to the second derivative of the Capital Market Line, to yield the optimal price,

$$
\begin{aligned}
& \left\{\left(1-z^{2}\right) d^{4} / d z^{4} 2 z \cdot d^{3} w / d z^{3}+\left[v(v+1) \mu^{2} /\left(1-z^{2}\right)\right] d^{2} / d x^{2} w\right\} / \\
& \left\{\left(1-z^{2}\right) d^{3} / d z^{3} 2 z d^{2} w / d z^{2}+\left[v(v+1) \mu^{2} /\left(1-z^{2}\right)\right] d w / d x\right\} \\
& =R_{j}-R_{f}-d / d x\left(\sigma_{j} / \sigma_{M}\right) \cdot\left(R_{M}-R_{f}\right)
\end{aligned}
$$

Large Cap US Growth Fund Theory. A mutual fund may identify itself as a large capitalization, US Growth Fund, which invests in large market capitalization, US stocks with growth rates among the leading $20 \%$ of growth rates of all domestic stocks traded on the S \& P 500, or large market capitalization index. Style investing is followed, with a Markowitz portfolio created, in accordance with Equation (39). Stocks are added to the portfolio if their standard deviation (risk) remains within 1 standard deviation of that of the market portfolio, or the S \& P 500. This portfolio will definitely locate on the Capital Market Line, as it does not have undue risk to lift its risk values above the Capital Market Line. An 
additional measure of risk may be applied from the Capital Asset Pricing Model, an extension of the Markowitz conceptualization. This is the stock's beta coefficient, the variation of stock returns with market portfolio returns. Given that the market portfolio's beta coefficient has a value of 1 , the average stock in this mutual fund should have a beta from $0.8-1.2$, or within a narrow band at or about 1. Systematic risk levels may not rise beyond 1.2. Non-systematic risk, measured by firm-specific risk, is likely to be minimal, given the minimization of covariance risk by holding highly diversified portfolios of hundreds of stocks. Given the nature of mutual funds, fund traders adhere to the philosophy of earning returns, just above the market return, while maintaining risk with the aforementioned 0.8 - 1.2 beta band.

There is no attempt to seek out investment opportunities with potential for future growth. There is no timing of purchases or sales to take advantages of preferable pricing. There is also no herding, as traders act individually, purchasing for their own inventories, rather than through collective action. They employ a buy-and-hold strategy, purchasing at any time. Since there are a number of large capitalization stocks, mutual fund traders may be purchasing continuously. They hold the portfolio for a long period of time, selling only if the risk of any stock rises beyond 1.2. After a certain period, specified by the investing philosophy of the employer, the securities are sold, and gains or losses assessed. [9] document the presence of liquidity traders during price run-ups. They do not take advantage of the increases in prices, before merger announcements, dividend announcements, or earnings surprises. They buy and sell, while informed traders only buy stock, that is rising in value. The presence of liquidity traders is so ubiquitous that informed traders hide large blocks of trades among the numerous small trades of liquidity traders. In Figure 7, the large cap fund is located at point $T$, at the intersection of the Capital Market Line and the indifference curve specifying utility, $A B . T$ is to the right, i.e. has higher risk than the market portfolio, $K$, lying at the intersection of the Markowitz Efficient Frontier and the Capital Market Line.

An inverse sine function [42] is used to represent the utility function of the mutual fund trader, ( $A B$ in Figure 7$)$. The pricing distribution for the price variation in large capitalization stock prices is the Capital Market Line. The optimal price, $T$, in Figure 7, is the intersection of these two distributions, measured by their optimization at the second derivative of each function, shown in Equation (40), below.

$$
\begin{aligned}
& 1 /(m+n) \cdot \sinh ^{m+1} z \cosh ^{n-1} z+(n-1) /(m+n) \int \sinh ^{m} z \cosh ^{n-z} d z \\
& =R_{j}-R_{f}-\sigma_{j} / \sigma_{M} \cdot\left(R_{M}-R_{f}\right)
\end{aligned}
$$

where, $m, n=$ constants, $z=$ random variable, specifying varying levels of satisfaction with risky investments, Taking the first derivative of Equation (40),

$$
\begin{aligned}
& 1 /(m+n) \cdot \cosh ^{m+1}-z \sinh ^{n-1} z+(n-1) /(m+n) \sinh ^{m} z \cosh ^{n-z} d z \\
& =d R_{j} / d x-R_{f}-\sigma_{j}^{\prime} / \sigma_{M}^{\prime} \cdot\left(d R_{M} / d x-R_{f}\right)
\end{aligned}
$$




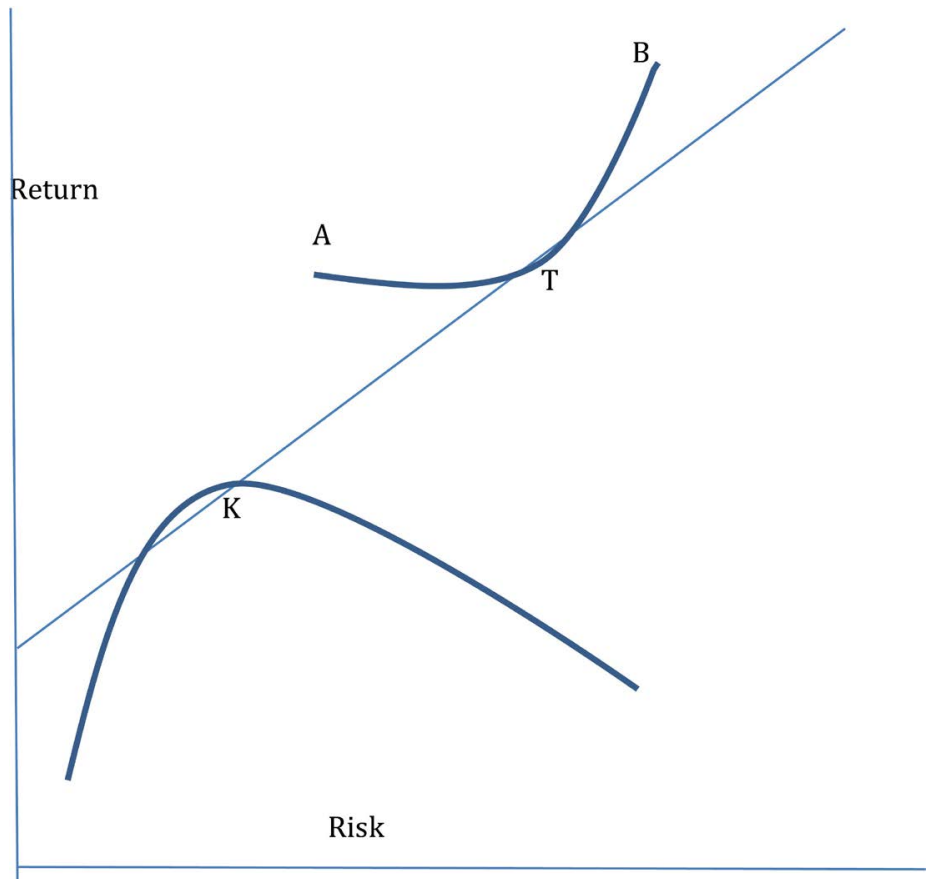

The large cap fund is at point $T$, at the intersection of the Capital Market Line and the inverse sine utility function, $A B$. $K$, is the market portfolio. Source: This Paper.

Figure 7. Optimal price of a large capitalization mutual fund.

where $R_{f}$ is assumed to be a constant Taking the second derivative of Equation (40),

$(m+1) /(m+n) \cdot \sinh ^{m} z(n-1) \cosh ^{n} z+m(n-1) /(m+n) \cosh ^{m-1}-z \sinh ^{n-1} d z$

$=d^{2} R_{j} / d x^{2}-R_{f}-\sigma_{j}^{\prime \prime} / \sigma_{M}^{\prime \prime} \cdot\left(d^{2} R_{M} / d x^{2}-R_{f}\right)$

Emerging Markets Mutual Fund. The final mutual fund portfolio that will be considered is a portfolio of emerging markets securities. [43] defines emerging markets as having purchasing power parity income at $10 \%-75 \%$ of the per capital income of the European Union, along with economic growth that in the past decade that has narrowed the gap with advanced economies, Emerging market countries have usually included, Argentina, Brazil, China, India, Indonesia, Mexico, Poland, South Africa, South Korea, Turkey, Egypt, Iran, Nigeria, Pakistan, Russia, and Saudi Arabia. Given the significant growth challenges that these countries have overcome to build new institutions, including banks, brokerages, hospitals, legal systems, city government, roads, bridges, and physical infrastructure, their average risk may be higher than the typical mutual fund portfolio. A less risk averse mutual fund manager may accept an emerging market portfolio, with risk tolerance typified by a Legendre integral, combined with the Arrow-Pratt coefficient of risk aversion, To reduce risk, the portfolio must be broadly diversified across countries, with equity investments in leading industries, such as banking, residential and commercial real estate, legal services, pharmaceuticals, hospitals, construction companies, food processing, and retail clothing. 


$$
\left(1-z^{2}\right) d^{2} / d z^{2} 2 z \cdot d w / d z+\left[v(v+1) \mu^{2} /\left(1-z^{2}\right)\right] w=0
$$

With degree $v$, and order $\mu$, with singularities at $\pm 1, \alpha$, as ordinary branch points $-\mu, v$, arbitrary complex constants. $Z=x+1, y, z$ real number is the interval $-1 \leq+1$.

The most appropriate pricing distribution is described by the International Capital Asset Pricing Model. The Capital Asset Pricing Model, which describes returns on domestic securities is an extension of the Capital Market Line, which separates total security risk into market risk, or the stock's sensitivity to market conditions, such as unemployment reports, and firm-specific risk found in the residuals, which is diversified. The International Capital Asset Pricing model, adds an additional item to assist in the valuation of global securities, $\beta_{1}\left(R_{f o}-R_{d}\right)$ where $\beta_{1}=$ sensitivity of domestic returns to changes in foreign currencies, and $\left(R_{f o}-R_{d}\right)=$ the additional return demanded by investors for investing in a foreign portfolio.

The Arrow-Pratt risk aversion is multiplied by the left side of Equation (43), and the right side is equated to the International Capital Asset Pricing Model (ICAPM) which acts as the pricing distribution,

$$
\left(1-z^{2}\right) d^{2} / d z^{2} 2 z \cdot d w / d z+\left[v(v+1) \mu^{2} /\left(1-z^{2}\right)\right]
$$

Taking second derivatives of Equation (43), and multiplying by the Arrow-Pratt Risk aversion, and equating to the second derivative of the International Capital Asset Pricing Model to yield the optimal price,

$$
\begin{aligned}
& \left\{\left(1-z^{2}\right) d^{4} / d z^{4} 2 z \cdot d^{3} w / d z^{3}+\left[v(v+1) \mu^{2} /\left(1-z^{2}\right)\right] d^{2} / d x^{2} w\right\} / \\
& \left\{\left(1-z^{2}\right) d^{3} / d z^{3} 2 z d^{2} w / d z^{2}+\left[v(v+1) \mu^{2} /\left(1-z^{2}\right)\right] d w / d x\right\} \\
& =R_{j}-R_{f}-d / d x\left(\sigma_{j} / \sigma_{M}\right) \cdot\left(R_{M}-R_{f}\right)+d / d x \beta_{1}\left(R_{f o}-R_{d}\right)
\end{aligned}
$$

Figure 8 shows, Point $A$, the location of the emerging markets portfolio on the Security Market Line, the International Capital Asset Pricing Model's graphical

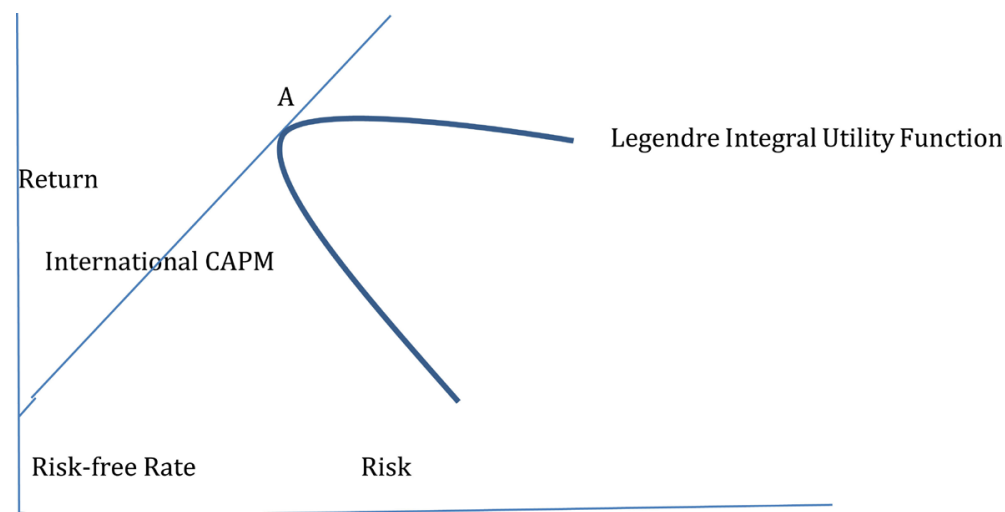

Point $A$ shows the emerging markets portfolio on the Security Market Line and the mutual fund trader's Legendre Integral Utility Function. Source: This Paper.

Figure 8. The optimal price for an emerging markets portfolio lying on the international capital asset pricing model's security market line. 
representation of its pricing distribution.

In summary, mutual fund strategies are dictated by corporate policy. Mutual fund traders trade for liquidity, i.e. to purchase and retain securities for longterm gains. They do not pursue entrepreneurial opportunities, or time the market or herd, to drive security price movements. They are usually forbidden from short selling, or undertaking high-risk investing.

Both the [23] and the [25] formulation assume that the second period is preferred to the first, as investors postpone current consumption to invest for growth in the second period, at the end of which returns are consumed. We support this assertion only for non-directional hedge funds. For directional hedge funds, timing only provides a signal of profits to be earned in the second period. It is the herding activity during the second period that is responsible for gains. For example, with a negative signal for a stock merger, modest gains are first taken from short selling stock. Timing merely indicates that more profits may be taken in the options market, It is herding, whereby groups of traders purchase put options in blocks that drives prices to a minimum, with the earning of maximum gain. For non-directional hedge fund strategies, risk aversion through intertemporal substitution, is implied. There is preference for the earning of gains during the lengthy second period, with unknown upward price movements, as opposed to the shorter, finite, limited profit potential of the first period. Accordingly, the examples of non-directional strategies, be they commodity trading, convertible arbitrage, or equity market neutral strategies, contain a reduced risk-aversion factor for the second period. Mutual funds engage in a buy-and-hold strategy, which assumes long-term growth, so that there is no time preference for any period.

\section{Conclusions and Recommendations for Future Research}

\subsection{Recommendations for Future Research}

Future research could develop equations to predict price movements in the event of more stringent regulatory restrictions on herding. Herding frequently occurs during price run-ups on the day before dividend announcements, positive earnings announcements, and on target stock in mergers. At this time, regulatory restrictions on herding activity are minimal, with any civil penalties being well within the financial capabilities of cash-rich hedge funds. Regulators may also monitor multimarket trading. Upon being subjected to short-sale constraints in the stock market, traders shift trading to the relatively less regulated options market, in a form of multimarket trading. Trading could be halted if regulators feel that hedge funds are driving prices excessively downwards, thereby destabilizing the market. Regulators may also be concerned that mutual fund traders, with the narrowest profit margins, are paying high transaction fees. Market makers typically increase transaction fees to uninformed mutual fund traders, to neutralize their losses to informed hedge fund traders.

How long can mutual fund managers continue to follow corporate practice 
and engage in low risk, market return-based trading ? The advent of the Internet has ushered in the instantaneous transmission of news throughout the world. Millenial investors, exposed to successful high-risk investing may abhor long-term, stable returns in favor of riskier equity investments. They may even consider very high risk-investments, such as foreign currency derivatives, or commodity options. This shift in risk preferences may lead mutual fund traders to engage in the arbitrage strategies of nondirectional hedge funds. It is unlikely that they would have the social connections to engage in herding. Future research should investigate shifts in risk tolerance of mutual fund traders.

Additional investigations could also trace directional hedge fund utility movements and price changes for events that generate negative signals, such as bankruptcy, reorganization, or merger deal failure, using the expressions developed in this paper. Research should also develop theoretical formulations for directional hedge fund activity during global macroeconomic events, such as Brexit, currency crises when a currency, or group of currencies lose up to $20 \%$ of their value within a few days, tariffs, or the global sell-off of stocks in December 2018. Non-directional hedge fund strategies may need to display superior timing abilities. For example, the paper has developed the formulation for the commodity trading strategy of short selling yen futures, using the proceeds to invest in New Zealand dollar futures. Future research should create formulations for a higherrisk commodity trading strategy of short selling yen futures, using the proceeds to invest in volatile Mexican pesos. As the Mexican peso is subject to sudden, unexpected devaluations, the trading formulation should first short yen, then invest in Mexican pesos, followed by timing to convert the Mexican pesos to yen prior to Mexican peso devaluation.

As volatility-based trading increases, traders may become less risk-averse, so that the risk-averse trader may become an anachronism. Research should ascertain if there is a mainstream reduction in risk aversion in society. Perhaps, we are seeing a fundamental shift in attitudes to risk, from risk aversion to risk-taking, given shifts in the global environment, including disruptive technology, tariffs, and slow growth in the industrialized west. As the shapes of utility functions will change, this study must be repeated for utility functions based on new statistical distributions.

\subsection{Conclusions}

This paper has created a novel framework for hedge fund investing, and mutual fund investing. The three components of directional hedge fund investing include seeking out entrepreneurial opportunities, timing, and herding. This framework has not been addressed in prior literature. Non-directional hedge funds engage in the seeking of entrepreneurial opportunities, and timing of purchases and sales. However, they do not engage in herding. For directional hedge funds, this paper has set forth the equations showing the rapid increase in prices and abnormal returns earned at optimal prices, from herding. 
Both of the hedge fund strategies require that traders demonstrate analytical abilities in comprehending market and security price movements. Mutual fund traders do not require superior analytical skills with buy-and-hold strategies, based on benchmarks created by their employers. The philosophy of following corporate practice prevails, even if the benchmark changes, such as different market benchmarks for sector funds, US growth funds, and international funds. Future research should assess whether the growing uncertainties of future economic environments may be met with established corporate practices in mutual fund investing. Possibly, riskier, and more innovative investing strategies will be more profitable than simple buy-and-hold.

This paper has fulfilled its objective of creating complex utility functions. Hitherto, utility functions have consisted of power utility functions, lognormal distribution, and hypergeometric distributions. We have presented a richer array of functions, including Bessel functions, hyperbolic cosine distributions, and Legendre integrals, Laplace distributions, quadratic utility functions, inverse sine distributions, and exponential distributions. Our utility functions distinguish between hedge funds and mutual funds, on the basis of risk aversion. Directional hedge fund traders are risk-takers. They believe in herding to influence prices, earning abnormal returns. Non-directional hedge fund traders are more riskaverse than hedge fund traders, eschewing market destabilization through herding. Mutual fund traders are the most risk-averse, making small volumes of trades, regardless of market conditions. Directional hedge fund traders make the highest gains with market opportunities, with mutual fund traders making the lowest gains. During the technology bubble, directional hedge fund traders sold early, achieving price gains, but no losses. Non-directional hedge fund traders made price gains, though some gains were lost, by not selling early. Mutual fund traders experienced the most losses, as they ignored market signals, owning securities that were rapidly losing value.

The Arrow-Pratt measure of risk aversion was created over fifty years ago, for developed countries. Perhaps, there are new measures of risk aversion, particularly for emerging markets, which are distinct from the markets in developed countries Emerging markets have early stage infrastructure development, and $7 \%$ - $9 \%$ growth rates, as opposed to established infrastructure, and 2\% - 3\% growth rates in developed countries. Wealth expectations that determine risk aversion in emerging markets may, thus, depend on a different set of macroeconomic variables. Another adjustment to risk aversion could be a measure for risk-taking that is closer to gambling for directional hedge fund traders, as initial success from risky investment stimulates the desire for further risk-taking [44]. Alternatively, arbitrage pricing theory [45] could be used to create a risk measure that depends upon a number of macroeconomic variables, instead of just a single variable, as implied in the Arrow-Pratt measure of $-U^{\prime \prime}(c) / U^{\prime}(c)$.

\section{Conflicts of Interest}

The author declares no conflicts of interest regarding the publication of this pa- 
per.

\section{References}

[1] Hedge Fund Report HFR (2018) HFR Global Hedge Fund Industry Report-Year End 2017 Published.

https://www.hedgefundresearch.com/news/hfr-global-hedge-fund-industry-reportq1-2018-published

[2] Williamson, C. (2018) Hedge Fund Assets End 2017 at Record \$ 3.2 Trillion-HFR. https://www.pionline.com/article/20180119/ONLINE/180119827/hedge-fund-assets -end-2017-at-record-32-trillion-8211-hfr

[3] Investor.gov. (2018) What Are Mutual Funds? https://www.investor.gov/investing-basics/investment-products/mutual-funds

[4] Carrns, A. (2018) Dave Ramsey's 12\% Solutions. https://bucks.blogs.nytimes.com/2011/05/13/dave-ramseys-12-solution/

[5] Kao, D.-L. (2002) Battle for Alphas: Hedge Funds versus Long-Only Portfolios. Financial Analysts Journal, 58, 16-36. https://doi.org/10.2469/faj.v58.n2.2520

[6] Sharpe, W.F. (1964) Capital Asset Prices: A Theory of Market Equilibrium under Conditions of Risk. The Journal of Finance, 19, 425-442.

[7] Agarwal, V. and Naik, N.Y. (2004) Risk and Portfolio Decisions Involving Hedge Funds. The Review of Financial Studies, 17, 63-98. https://doi.org/10.1093/rfs/hhg044

[8] Bali, T.G., Brown, S.J. and Caglayan, M.O. (2011) Do Hedge Funds Exposures to Risk Factors Predict Their Future Returns? Journal of Financial Economics, 101, 36-68. https://doi.org/10.1016/j.jfineco.2011.02.008

[9] Easley, D.O., O’Hara, M. and Srinivs, P.S. (1998) Option Volume and Stock Prices: Evidence on Where Informed Traders Trade. The Journal of Finance, 53, 431-465. https://doi.org/10.1111/0022-1082.194060

[10] Abraham, R., Harrington, C.W. and Williams, A.A. (2011) Multimarket Trading at Merger Announcement and Completion. Journal of Derivatives and Hedge Funds, 17, 186-197. https://doi.org/10.1057/jdhf.2011.13

[11] Fung, W. and Hseih, D.A. (1997) Empirical Characteristics of Dynamic Trading Strategies: The Case of Hedge Funds. The Review of Financial Studies, 10, 275-302. https://doi.org/10.1093/rfs/10.2.275

[12] Caglayan, M.O. and Ulutas, S. (2014) Emerging Market Exposures and the Predictability of Hedge Fund Returns. Financial Management, 43, 149-180. https://doi.org/10.1111/fima.12029

[13] Markowitz, H.M. (1952) Portfolio Selection. The Journal of Finance, 7, 77-91.

[14] Chatterji, A.K., de Figeuiredo Jr., R.J.P. and Rawley, E. (2016) Learning on the Job? Employee Mobility in the Asset Management Industry. Management Science, 62, 2765-3084. https://doi.org/10.1287/mnsc.2015.2276

[15] Aggarwal, R.K., Buchan, J. and Saint-Laurent, P. (2012) Qualitative Hedge Fund Characteristics and Fund Performance: Changes over Time. Journal of Alternative Investments, 15, 8-23. https://doi.org/10.3905/jai.2012.15.2.008

[16] Bruder, B., Koudiraty, A., Darolles, S. and Roncalli, T. (2011) Portfolio Allocation of Hedge Funds. http://dx.doi.org/10.2139/ssrn.1804511

[17] Maillard, S., Roncalli, T. and Teiletche, J. (2010) The Properties of Equally Weighted Risk Contribution Portfolios. The Journal of Portfolio Management, 36, 
60-70. https://doi.org/10.3905/jpm.2010.36.4.060

[18] Jondeau, E. and Rockinger, M. (2012) On the Importance of Time Variability in Higher Moments for Asset Allocation. Journal of Financial Econometrics, 10, 84-123. https://doi.org/10.1093/jjfinec/nbr006

[19] Martinelli, L. and Ziemann, V. (2010) Improved Estimates of Higher-Order Components and Implications for Portfolio Selection. The Review of Financial Studies, 23, 1467-1502. https://doi.org/10.1093/rfs/hhp099

[20] Morton, D.P. and Popova, I. (2013) Modeling Hedge Fund Leverage via Power Utility with Subsistence. Journal of Derivatives and Hedge Funds, 19, 77-85. https://doi.org/10.1057/jdhf.2013.4

[21] Siegmann, A. and Lucas, A. (2002) Explaining Hedge Fund Investment Styles by Loss Aversion. Discussion Paper, Tinbergen Institute, Vrije Universiteit, Amsterdam.

[22] Abbas, A.E. (2012) Valuing Change in Investment Opportunities. Operations Research, 60, 1451-1460. https://doi.org/10.1287/opre.1120.1092

[23] Traeger, C.P. (2014) Why Uncertainty Matters: Discounting under Intertemporal Risk Aversion and Ambiguity. Economic Theory, 56, 627-664. https://doi.org/10.1007/s00199-014-0800-8

[24] Treynor, J. and Black, F. (1973) How To Use Security Analysis to Improve Portfolio Selection. Journal of Business, 46, 66-86. https://doi.org/10.1086/295508

[25] Henriksson, R.D. and Merton, R.C. (1981) On Market Timing and Investment Performance. II. Statistical Procedures for Evaluating Forecasting Skills. The Journal of Business, 54, 513-533. https://doi.org/10.1086/296144

[26] Kharazmi, O. and Saadatinik, A. (2016) Hyperbolic Cosine-F Family of Distributions with an Application to Exponential Distribution. Gazi University Journal of Science, 29, 811-829.

[27] Schmidt, D.F. and Makalic, E. (2009) Universal Models for the Exponential Distribution. IEEE Transactions on Information Theory, 55, 3087-3090. https://doi.org/10.1109/TIT.2009.2018331

[28] Miyahara, Y. (2012) Option Pricing in Incomplete Markets. Imperial College Press, London.

[29] Abraham, R. and Harrington, C.W. (2011) Differential Information in Option Volume and Stock Volume. Journal of Derivatives and Hedge Funds, 17, 298-312. https://doi.org/10.1057/jdhf.2011.23

[30] Pearson, K. (1929) Inequalities for Moments of Frequency Functions and for Various Statistical Constants. Biometrika, 21, 361-375. https://doi.org/10.1093/biomet/21.1-4.361

[31] Wollscheid, C. (2012) Rise and Burst of the Dotcom Bubble: Causes, Characteristics, Examples. GRIN Verlag, Munich.

[32] Ofek, E. and Richardson, M. (2002) The Valuation and Market Rationality of Internet Stock Prices. Oxford Review of Economic Policy, 18, 265-287. https://doi.org/10.1093/oxrep/18.3.265

[33] Abreu, D. and Brunnermeier, M.K. (2002) Synchronization Risk and Delayed Arbitrage. Journal of Financial Economics, 66, 341-360. https://doi.org/10.1016/S0304-405X(02)00227-1

[34] Clement, M.B. and Tse, S.Y. (2005) Financial Analyst Characteristics and Herding Behavior in Forecasting. The Journal of Finance, 60, 307-341. https://doi.org/10.1111/j.1540-6261.2005.00731.x 
[35] Fama, E.F. (1984) Forward and Spot Exchange Rates. Journal of Monetary Economics, 14, 319-338. https://doi.org/10.1016/0304-3932(84)90046-1

[36] Gorton, G.B., Hayashi, F. and Rouwenhorst, K.G. (2013) The Fundamentals of Commodity Futures Returns. Review of Finance, 17, 35-105. https://doi.org/10.1093/rof/rfs019

[37] Park, S.Y. and Bera, A.K. (2009) Maximum Entropy AutoRegressive Conditional Heterokedasticity Model. Journal of Econometrics, 150, 219-230. https://doi.org/10.1016/j.jeconom.2008.12.014

[38] Szymanowska, M., De Roon, F., Nijman, T. and Van den Goorbergh, R. (2014) An Anatomy of Commodity Futures Risk Premia. The Journal of Finance, 69, 453-482. https://doi.org/10.1111/jofi.12096

[39] Yu, C.-Y. (2002) Evaluating Cutoff Criteria of Model Fit Indices for Latent Variable Models with Binary and Continuous Outcomes. Unpublished Doctoral Dissertation, University of California, Los Angeles.

[40] Lustig, H., Roussanov, N. and Verdelhan, A. (2011) Common Risk Factors in Currency Markets. The Review of Financial Studies, 24, 3731-3777.

https://doi.org/10.1093/rfs/hhr068

[41] Statistics New Zealand (2014) Archived from the Original on 13 January 2015.

[42] Abramowitz, M. and Stegun, I.A. (1964) Handbook of Mathematical Functions with Formulas, Graphs, and Mathematical Tables. National Bureau of Standards Applied Mathematics Series, U.S. Department of Commerce, Washington DC.

[43] Kvint, V. (2009) The Global Emerging Market: Strategic Management and Economics. Routledge, New York, London.

[44] Zhou, K., Tang, H., Sun, Y., Huang, G.-H., Rao, L.-L. and Liang, Z.-Y. (2012) Belief in Luck or in Skill: What Locks People into Gambling? Journal of Gambling Studies, 28, 379-391. https://doi.org/10.1007/s10899-011-9263-Z

[45] Ross, S.A. (1976) The Arbitrage Theory of Capital Asset Pricing. Journal of Economic Theory, 13, 341-360. https://doi.org/10.1016/0022-0531(76)90046-6 